\title{
HUMAN CHONDROCYTES IN TRIDIMENSIONAL CULTURE
}

\author{
C. BASSLEER, Ph. GYSEN, J. M. FOIDART, \\ R. BASSLEER, AND P. FRANCHIMONT \\ Laboratory of Radioimmunology, Institute of Pathology B 23, University of Liège, Sart Tilman, 4000 Liege, \\ Belgium (C. B., Ph. G., P. F.), Laboratory of Histology and Cytology, University of Liège, Rue des \\ Pitteurs, 20-4020 Liège, Belgium (C. B., R. B.), and Laboratory of Dermatology, B 23, \\ Institute of Pathology, University of Liège, Sart Tilman, 4000 Liège, Belgium (J. M. F.)
}

(Received 11 October 1984; accepted 16 September 1985)

\begin{abstract}
SUMMARY
Cartilage was taken from the macroscopically normal part of human femoral heads immediately after orthopedic surgical operations for total prothesis consecutive to hip arthrosis. After clostridial collagenase digestion and repeated washings, chondrocytes $\left(10^{6}\right.$ cells) were cultivated in a gyrotory shaker $(100 \mathrm{rpm})$. Under these conditions, cells were kept in suspension and after 3 to $5 \mathrm{~d}$ formed a flaky aggregate which, on Day 10, became dense. These chondrocytes were morphologically differentiated: they had a round shape, were situated inside cavities, and were surrounded by a new matrix. Histochemical methods showed the presence of collagen and polysaccharides in cell cytoplasm and in intercellular matrix, and the immunofluorescence method using specific antisera (anticartilage proteoglycans and anti-type II collagen) showed that these two constituents were in intercellular matrix. The measurement of the amounts of proteoglycans (PG) released into culture medium and those present in chondrocyte aggregate (by a specific PG radioimmunoassay) showed a maximum production on Days 3 to 5 of culture, then the production decreased and stabilized (from Day 10 to the end of culture). The observed difference between the amounts of $P G$ in aggregates after $20 \mathrm{~d}$ and those after $2 \mathrm{~h}$ of culture demonstrated that PG neosynthesis did occur during cultivation. This conclusion was supported by other results obtained by $\left[{ }^{14} \mathrm{C}\right]$ glucosamine incorporation in chondrocyte aggregates. Moreover, the aggregate fresh weight related to cell number (appreciated by DNA assay) increased significantly with culture duration. Three-dimensional chondrocyte culture represents an interesting model: chondrocytes were differentiated morphologically as well as biosynthetically and synthesized a new cartilage matrix.
\end{abstract}

Key words: chondrocytes; suspension culture; cartilage; differentiation; tridimensional culture.

\section{INTRODUCTION}

It is well known that chondrocytes are characterized by their ability to synthesize an extracellular matrix. This matrix is essentially composed of type II collagen $(31,44)$ and cartilage proteoglycan (PG) $(20,22,23,29,36)$. Proteoglycans are covalently linked to hyaluronic acid in a supramolecular complex (21). Metabolic functions of chondrocytes have mainly been studied by cultivating in monolayers chick embryo chondrocytes $(4,11,30,32,43)$ or mammalian articular chondrocytes $(9,25,26)$ and human chondrocytes (19). Under these experimental conditions, chondrocytes in culture usually have an unstable phenotype and tend to dedifferentiate $(1,2,35,45,46)$. To avoid this difficulty, chondrocytes have been cultivated in agarose gel $(6,24)$ or in organ culture $(7,28)$. Chondrocyte cultivation in three dimensions and in suspension has been proposed $(5,12,33,40,41)$, but such a model has not been studied in detail up to now.

The aim of this work was to cultivate chondrocytes from human articular cartilage in three dimensions and to study their eventual morphological differentiation and matrix production (proteoglycans and collagen).

\section{Materials AND MethodS}

Human chondrocytes were cultivated in Dulbecco's modification of Eagle's medium (DMEM, Flow Labs) supplememted with $10 \%$ fetal bovine serum (GIBCO, Ghent, Belgium)vand ascorbic acid $(50 \mu \mathrm{g} / \mathrm{ml})$. Cartilage was taken from the macroscopically normal part of human femoral heads immediately after surgery. This hyaline cartilage was cut into small fragments which were then digested by clostridial collagenase (Boehringer-Mannheim $\mathbf{G m b H}$, Germany; 1 $\mathrm{mg} / \mathrm{ml})$ in carbonate-bicarbonate buffer $\left(\mathrm{CaCl}_{2} \mathrm{l} \mathrm{mM}\right.$ adjusted to $\mathrm{pH}$ 7.4) during $24 \mathrm{~h}$. This way, chondrocytes were separated from their matrix. The cellular suspension was centrifuged ( $1500 \mathrm{rpm}, 5 \mathrm{~min}$ ) and the pellet was suspended in culture medium. After six successive washings and cen- 
trifugations (1500 rpm, $5 \mathrm{~min}$ ) the pellet was suspended in the culture medium. Cells were then put into suspension $\left(10^{6}\right.$ cells/10-ml flask, Sovirel, containing $3 \mathrm{ml}$ of culture medium). Flasks were placed in a gyrotory shaker $(100 \mathrm{rpm})$. Cultures were maintained at $37^{\circ} \mathrm{C}$ in an air atmosphere with $5 \% \mathrm{CO}_{2}$.

Histological and histochemical analysis. Chondrocyte aggregates (1.5 to $2.5 \mathrm{~mm}$ diameter) were fixed with Bouin liquid after 9 to $30 \mathrm{~d}$ in culture. Sections $(1-\mu \mathrm{m}$ thick) of aggregates embedded in paraffin were stained with hematoxylin and eosin, light green, periodic acid Schiff (PAS), or Alcian blue (light microscopy).

Transmission electron microscope analysis. Aggregates were fixed with glutaraldehyde $12.5 \%$ in cacodylate buffer). Ultrathin sections of aggregates embedded in Epon and contrasted with uranyl acetate and lead citrate were studied with a transmission electron microscope $(800$ kV, Philips EM 301).

Immunocytochemical study. Type II collagen, cartilage proteoglycans, and laminin were sought by the immunofluorescence method applied to semithin sections $(1 \mu \mathrm{m})$ of chondrocyte aggregates fixed with formol and embedded in paraffin (42).

Specific antisera were used. Type II collagen antiserum, induced in guinea pig (type II collagen, isolated from bovine cartilage) was obtained from Foidart et al. (13). The specificity of antitype II collagen has been established as follows: (a) by the hemaglutination method-there was no cross-reaction of antitype II collagen with any other type of collagen $(13,14)$; (b) by the radioimmunological method-there was no reaction with other types of collagen and it still reacted with type II collagen after a preincubation in presence of other types of collagen $(16,38)$.

Human cartilage proteoglycans antiserum was induced in rabbits by injections of human cartilage PGs. The specificity of this antiserum was assessed by the radioimmunological method (19). There was no crossreaction with other connective tissue components such as type I, II, III collagens, fibronectin, or hyaluronic acid. Furthermore, the antibodies were directed against the core protein of cartilage $\mathrm{PGs}$ whereas chondroitin and keratan sulfate were not immunoreactive with the antiserum. Finally, the antibodies were species-specific (rat and chick cartilage PG did not cross-react) and tissue-specific (proteoglycans from bone, liver, and lung did not cross-react in cartilage $\mathrm{PGs}$ radioimmunoassay). Laminin antiserum $(15,16)$ was used as a control, because laminin is not present in normal cartilage.
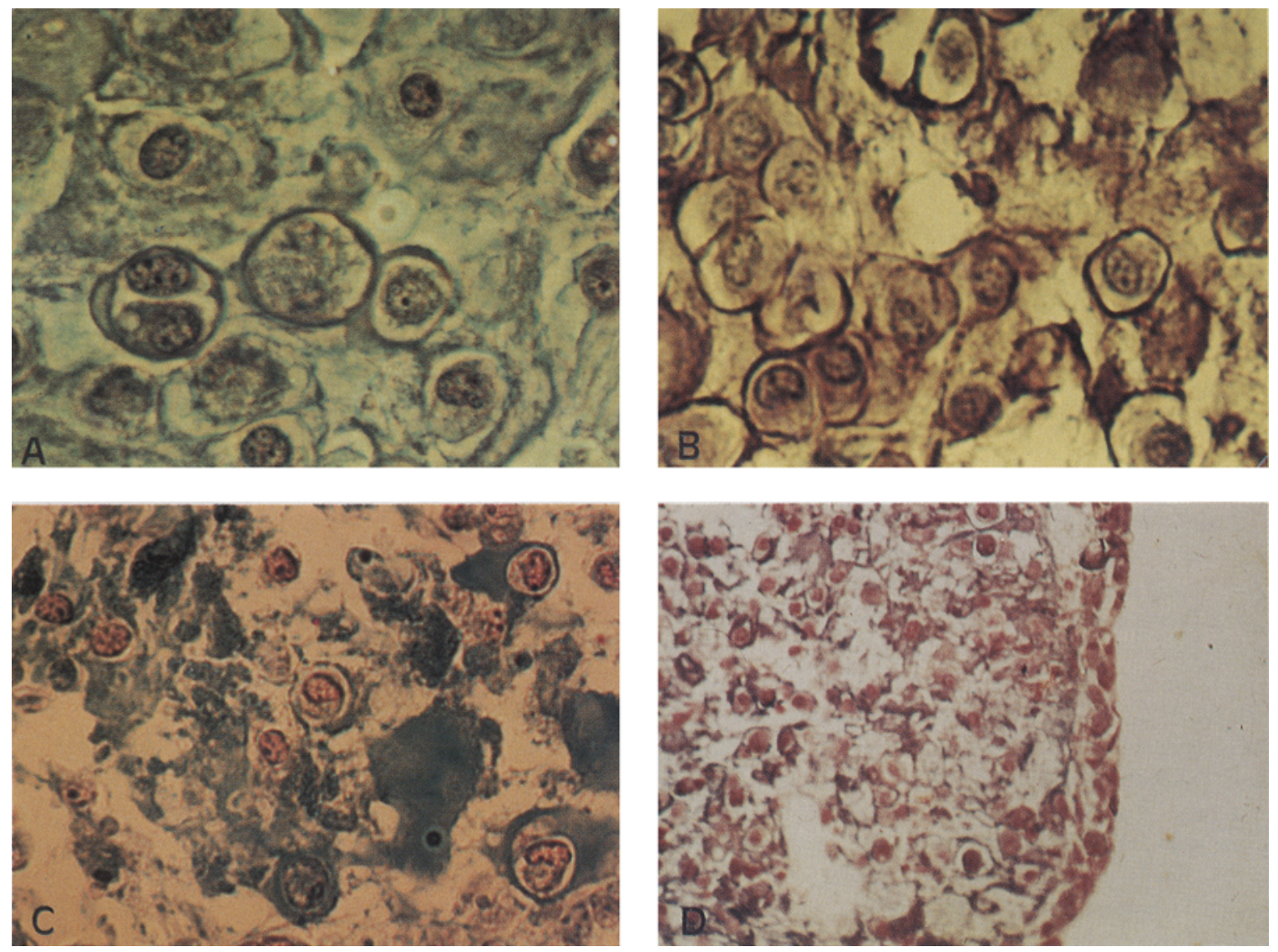

Fig. 1. Sections of human chondrocyte aggregates stained with hematoxylin and eosin $(9 \mathrm{~d}$ in culture). $A$, with PAS $(29 \mathrm{~d}$ in culture). $\times 465$. $B$, with light green and Kernechtrot $(9 \mathrm{~d}$ in culture). $\times 465 . C$, with Alcian blue ( $30 \mathrm{~d}$ in culture). $\times 237$. $D$, a superficial layer of flat cells delimits the aggregates. Chondrocytes are situated inside small cavities embedded in a newly synthesized matrix. $\times 86$. 
For all antisera, these three controls were applied: sections of aggregates were incubated for $30 \mathrm{~min}$ in the absence of antiserum, in the presence of nonimmunized rabbit serum, and in the presence of specific antiserum, the antibodies of which had been previously adsorbed with antigen excess.

Sections of chondrocyte aggregates after different culture durations, $(9$ to $30 \mathrm{~d})$ were treated for $30 \mathrm{~min}$ with testicular hyaluronidase $(20 \mathrm{mg} / \mathrm{ml}$ phosphate buffered saline (PBS), washed five times in PBS, incubated for 30 min with normal goat serum, then put in contact with antiserum $(1 / 20)$ (1 h), washed with PBS, (5 times), incubated with anti-Ig induced in goat and chemically coupled with fluorescein or rhodamin, and washed again. Chondrocyte aggregate sections were observed with a fluorescent microscope.

Radioimmunoassay of cartilage proteoglycans. Proteoglycans released into culture medium and PG present in chondrocyte aggregate were measured according to the radioimmunoassay described by Gysen et al. $(18,19)$.

Culture media were assayed for PGs without treatment. Chondrocyte aggregates were washed three times with PBS, then dissolved in $4 M$ guanidinium chloride containing epzyme inhibitors (37) under agitation. After $24 \mathrm{~h}$, the extracts were centrifugated and supernatants were dialyzed against PBS, then assayed for PG.
The radioimmunoassay was performed in a $0.4-\mathrm{ml}$ incubation volume constituted with $0.1 \mathrm{ml}$ of the tracer solution $(15000$ to $20000 \mathrm{cpm}$ of $\mathrm{PG}$ labeled with [125]iodine by chloramine $T$ method), $0.1 \mathrm{ml}$ of antiserum anti-PG diluted at 1:5000 in PBS containing 5 $\mathrm{g} / 1$ bovine serum albumin (incubation buffer) and $0.2 \mathrm{ml}$ of several dilutions of the material to be measured (conditioned culture medium or chondrocyte aggregate extract) or the unlabeled antigen ranging from 0.1 to 500 $\mathrm{ng} /$ tube (reference curve). After $4 \mathrm{~d}$ at $4^{\circ} \mathrm{C}$, the labeled PG antibody complexes were separated by double precipitation by adding $0.1 \mathrm{ml}$ of $1: 20$ dilution of donkey antirabbit Ig $G$ serum and $0.1 \mathrm{ml}$ of a $1: 100$ dilution of normal rabbit serum. After $48 \mathrm{~h}$ at $4^{\circ} \mathrm{C}$, the precipitate was separated by centrifugation after addition of $2 \mathrm{ml}$ of incubation buffer containing $200 \mathrm{mg} / 1$ of microcristalline cellulose and $2.5 \mathrm{ml} / 1$ of Tween 20 . The radioactivity was measured in a gamma counter.

$\left[{ }^{14} \mathrm{C}\right]$ Glucosamine incorporation into chondrocyte aggregates. To study PG synthesis, chondrocytes were incubated after various culture durations, in culture medium containing $\left[\mathrm{D}-1-{ }^{14} \mathrm{C}\right] \mathrm{glucosamine}$ hydrochloride (Amersham, Arlington Heights, IL; $2 \mu \mathrm{Ci} / \mathrm{ml} ; 56.8$ $\mathrm{mCi} / \mathrm{mmol}$. After $24 \mathrm{~h}$, chondrocyte aggregates were washed in PBS ( $3 \times 5 \mathrm{~min})$, incubated for $1 \mathrm{~h}$ in PBS containing $5 \mathrm{~g} / \mathrm{l}$ glucosamine, washed again, and

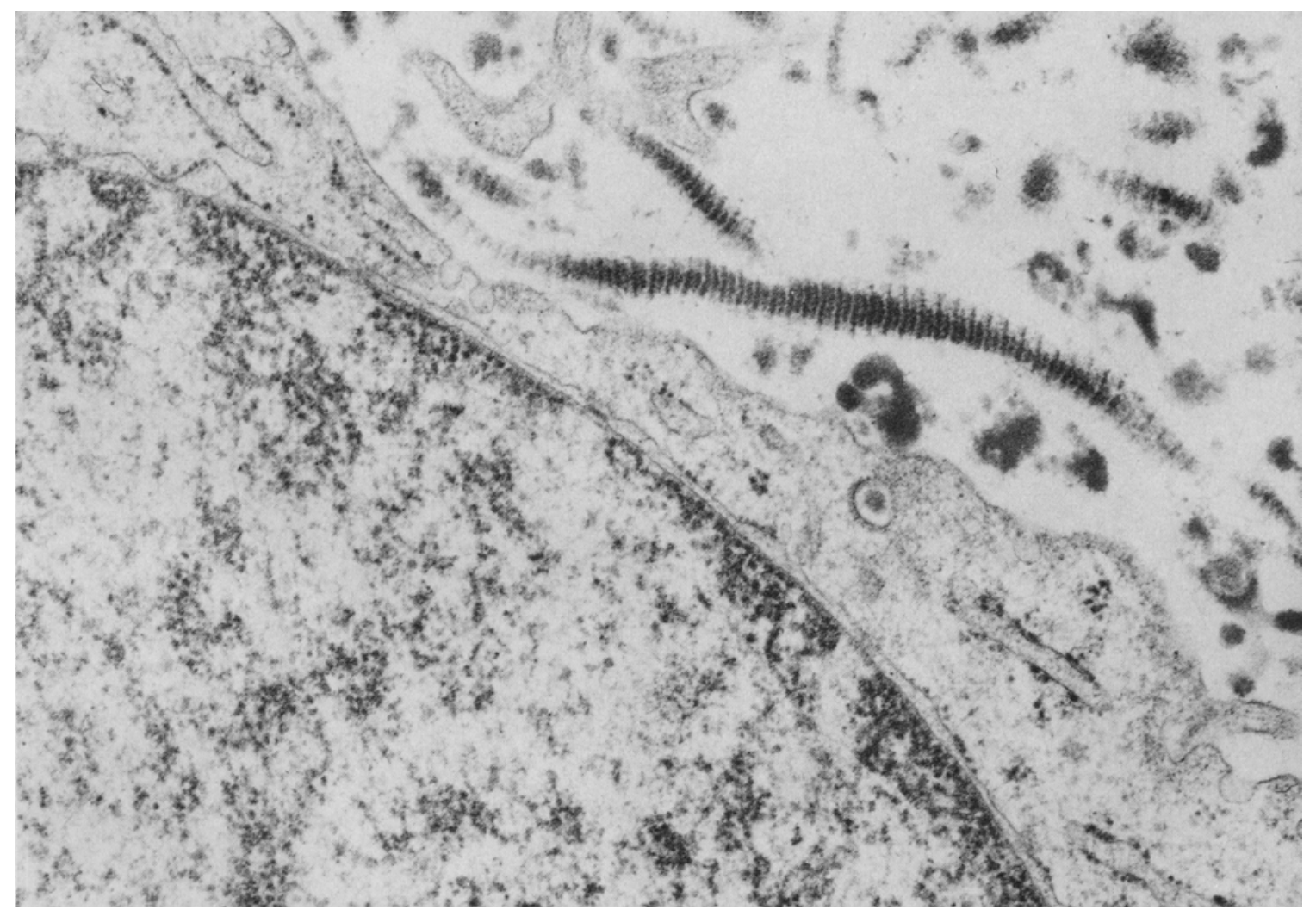

Fig. 2. Electron microscope observation of a human chondrocyte in one aggregate $(10 \mathrm{~d}$ in culture). Close to a portion of the nucleus, the cytoplasm contains developed granular endoplasmic reticulum. In extracellular matrix, homogeneous material and striated collagen microfibrils were present. $\times 46020$. 
ultrasonicated. Incorporated radioactivity was counted ( $\beta$-counter), and DNA content in chondrocyte aggregates was measured according to the fluorimetric method of
Labarca and Paigen (27). Incorporated radioactivity was reported to microgram DNA. Incorporated radioactivity was studied every $3 \mathrm{~d}$ (5 to $25 \mathrm{~d}$ in culture) in three
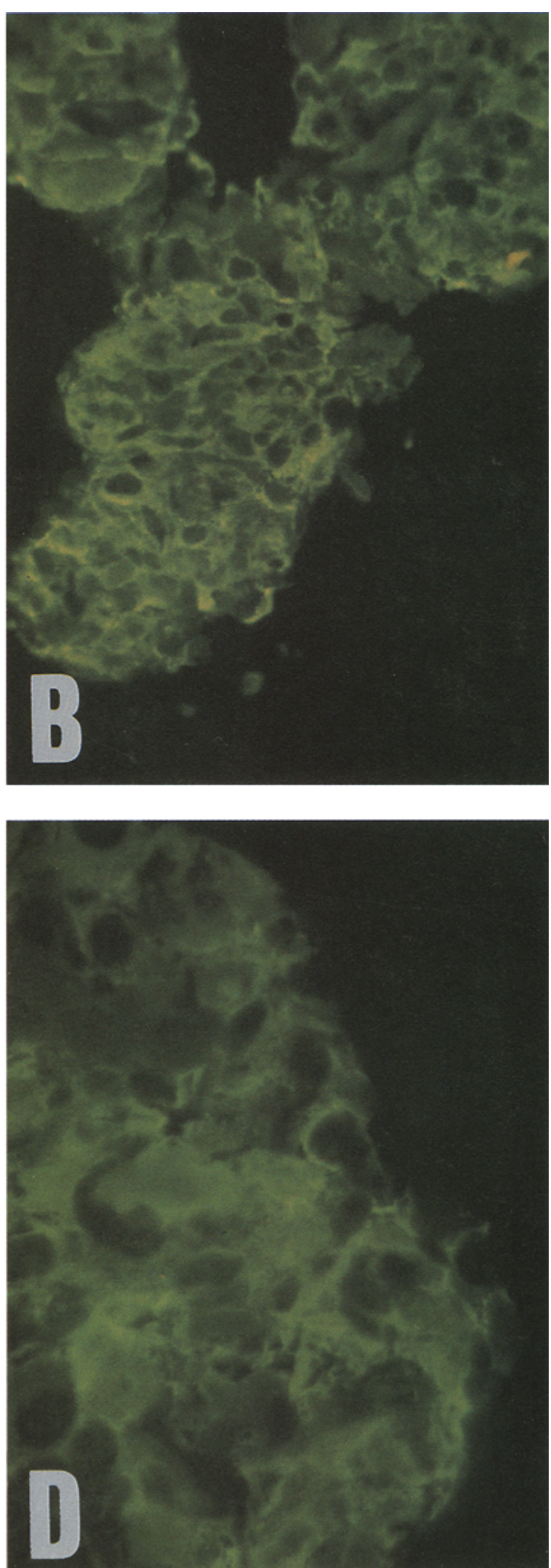

Fig. 3. Immunofluorescence method applied to thin sections in chondrocyte aggregates demonstrates the presence of type II collagen $(A-C)$ and cartilage proteoglycans $(B-D) . A-B 10 \mathrm{~d}$ in culture; $C-D 30 \mathrm{~d}$ in culture. $A, C, D \times 319 ; B$ $\times 120$. 


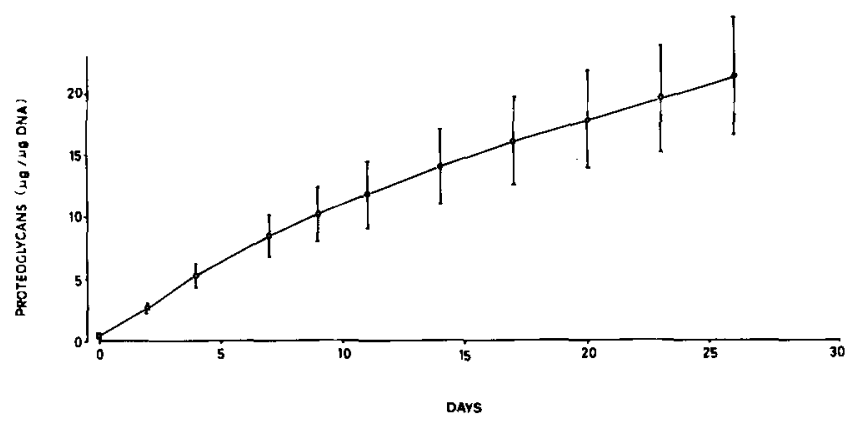

FIG, 4. Mean curve obtained for five individual experiments concerning proteoglycans released into culture medium as a function of culture duration. Cumulative values; mean \pm one SD.

chondrocyte aggregates in each case. As a control for $\left[{ }^{14} \mathrm{C}\right]$ glucosamine incorporation, three aggregates were previously fixed in absolute ethanol.

\section{RESULTS}

Dissociated human chondrocytes cultivated under these conditions formed aggregates after 3 to $5 \mathrm{~d}$. These aggregates tended to condense; their diameter was around $2 \mathrm{~mm}$. They were kept in excellent condition for more than $1 \mathrm{mo}$. in vitro.

Histological and histochemical analysis-light microscopy. Sections of aggregates after various durations of culture have been stained by different methods: two types of chondrocytes can be distinguished in aggregates. A layer of flat cells delimited the latter-aggregate. Inside aggregates, cells were quite spherical. Between them, abundant newly synthesized intercellular material (matrix) was present in which small cavities contained living chondrocytes (Fig. $1 A-D$ ). Periodic acid Schiff and Alcian blue stainings demonstrated the presence of polysaccharides in intercellular matrix and in chondrocyte cytoplasm (Fig. 1 B-D). Light green staining showed the presence of collagen in intercellular matrix and on the edges of small cavities, which were particularly positive (Fig. $1 \mathrm{C}$ ). Identical aspects were observed after 9, 29, and $30 \mathrm{~d}$ of culture. Mitotic cells were present, usually at the aggregate periphery; their number decreased with culture duration.

Transmission electron microscope analysis. Chondrocytes presented a well-developed Golgi apparatus. Granular endoplasmic reticulum was relatively abundant and contained synthesized material in cisternae. Cytoplasmic granules contained homogeneous granular material. Microfilaments and microtubules were present in the cytoplasm. Microvesicles were often associated with plasma membrane. Intercellular matrix contained abundant microfibrils which were usually striated (collagen) (Fig. 2).

Immunocytochemical study. With specific antisera, type $I I$ collagen and PGs were demonstrated to be present in intercellular matrix and in cell cytoplasm (Fig. 3). Usually, the intensity of the reaction was lower at the aggregate periphery. Similar results were observed in chondrocyte aggregates after 10,16 , and $29 \mathrm{~d}$ of culture.
Quantitative and kinetic study of PG synthesis. To study the formation of cartilage matrix by chondrocytes in three-dimensional culture, the amounts of PG present in chondrocyte aggregates and in conditioned culture medium were measured by specific human cartilage PG radioimmunoassay.

Figure 4 represents cumulative PG production in culture medium for five different experiments. For each experiment, three flasks were used at a time; each flask contained one chondrocyte aggregate. Under identical conditions, the PG amount in chondrocyte aggregates increased as a function of culture duration (Fig. 5).

Chondrocyte aggregate fresh weight also increased as a function of culture duration, especially during the first days of culture (Table 1); up to Days 8 to 10 chondrocyte aggregates were flaky; then the aggregates were clearly formed (Days 10 to 15 in culture). Aggregate fresh weight related to cell number (appreciated by DNA content) increased progressively (after 4 d: 2.2 土 0.38 $\mathrm{mg} / \mu \mathrm{g}$ DNA, but $3.25 \pm 0.35 \mathrm{mg} / \mu \mathrm{g}$ DNA after $20 \mathrm{~d}$ in culture).

$\left[{ }^{14} \mathrm{C}\right]$ glucosamine incorporation into chondrocyte aggregates. $\left[{ }^{14} \mathrm{C}\right]$ Glucosamine incorporation into hyaluronic acid and keratin sulfate was studied as a function of culture duration (Fig. 6). Values were expressed as disintegrations per minute per microgram DNA. Figure 6 shows maximal incorporation when cultures were 10-d-old, after which incorporation intensity decreased, but some incorporation was clearly maintained during more than $25 \mathrm{~d}$.

\section{Discussion}

It is well established that chondrocytes, when liberated from their matrix by digestion and then cultivated in vitro in monolayers, usually rapidly lose their morphological and biochemical characteristics, assume a fibroblastic phenotype, and actively divide $(1,2,8,10,40,47)$. When cultivated in a defined medium, in monolayers, rabbit

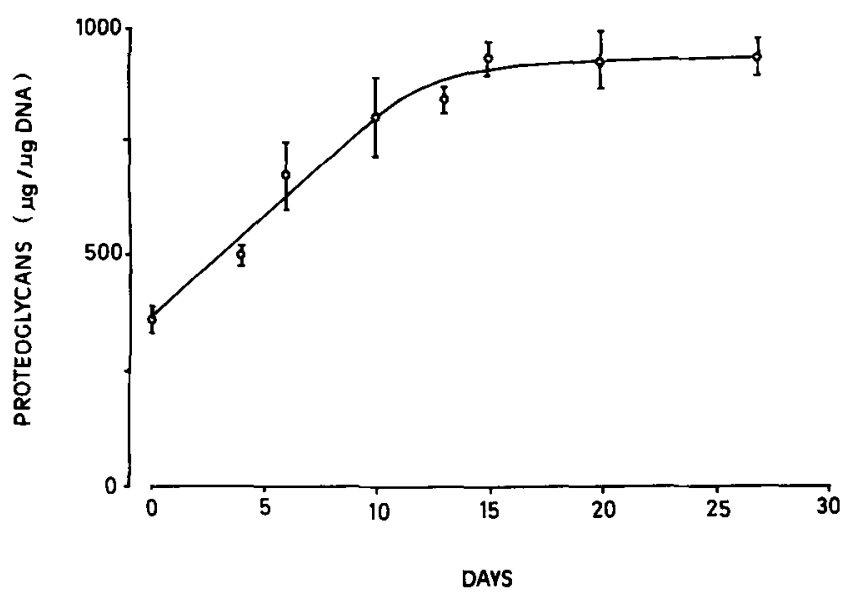

FIG. 5. Mean curve obtained for five individual experiments related to proteoglycans measured inside chondrocyte aggregates as a function of culture duration. Mean \pm one SD. 
TABLE 1

\section{CHONDROCYTE AGGREGATE FRESH WEIGHT} RELATED TO MICROGRAM OF DNA

\begin{tabular}{cc}
\hline Culture Duration & Fresh Weight (mg/ug DNA) \\
\hline $2 \mathrm{~h}$ & $1.3 \pm 0.10$ \\
$4 \mathrm{~d}$ & $2.2 \pm 0.38$ \\
$6 \mathrm{~d}$ & $2.62 \pm 0.20$ \\
$10 \mathrm{~d}$ & $2.78 \pm 0.40$ \\
$13 \mathrm{~d}$ & $2.84 \pm 0.30$ \\
$15 \mathrm{~d}$ & $2.96 \pm 0.58$ \\
$20 \mathrm{~d}$ & $3.25 \pm 0.35$ \\
\hline
\end{tabular}

articular chondrocytes proliferate and synthesize type II collagen (3). The behavior of rabbit articular chondrocytes in suspension is quite different from that in monolayer culture; cells deposit metachromatic material (17). When rabbit chondrocytes cultured in monolayer flasks are trypsinized and transferred to spinner bottles, proliferation is greatly reduced. Much metachromatic material is deposited by the aggregated cells (41). Furthermore, suspension conditions result in the production of type II collagen. Our results showed that when cultivated under three-dimensional conditions, human chondrocytes expressed their morphological differentiation; they were spherical and lived inside small cavities in a newly synthesized matrix. Only cells at the aggregate periphery had a fibroblastic shape. These morphological aspects persist during a period of culture that was relatively long (1 mo.). Ultrastructurally, chondrocytes present signs of intense secretory activity (developed Golgi apparatus, abundant granular endoplasmic reticulum, cytoplasmic granules).

Chondrocyte differentiation was demonstrated not only by morphological analysis, but also by the presence of normal constituents of intercellular matrix; type II collagen and cartilage PGs. By the histological method (light green staining) collagen was detected in cell cytoplasm and in matrix; the immunofluorescent method also showed the presence of type II collagen in intercellular matrix and in cell cytoplasm.

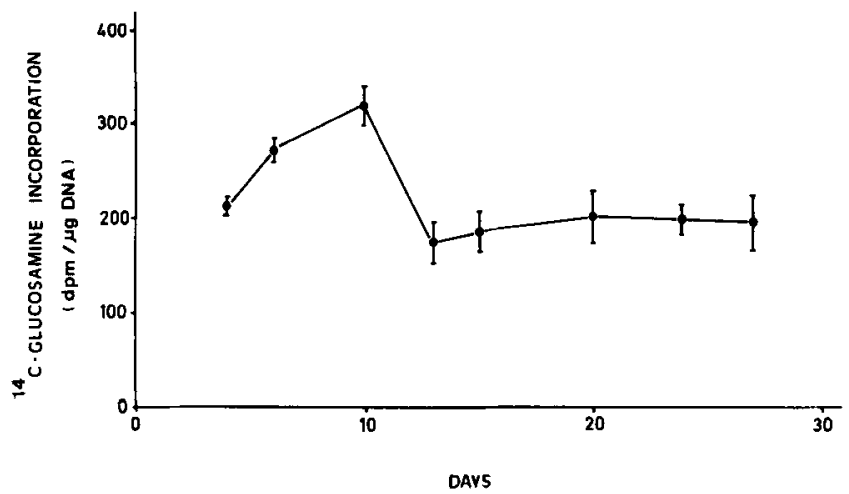

FIG. 6. $\left[{ }^{14} \mathrm{C}\right]$ Glucosamine incorporation into aggregates after different culture durations. Bars $=$ mean values \pm one SD.
Histochemical methods (PAS and Alcian blue stainings) and immunofluorescence using specific antiserum anticartilage PGs demonstrated the presence of cartilage PG in chondrocyte aggregate. Moreover, large amounts of cartilage PG assayed by the radioimmunologic method were detected in conditioned culture medium and in chondrocyte aggregates. There was an important increase of PG in culture medium and in chondrocyte aggregate as compared to values observed after $2 \mathrm{~h}$ in culture. Thus, we can consider that $P G$ assayed in chondrocyte aggregate and in culture medium corresponded to newly synthesized material. Furthermore, electron microscope observations showed that chondrocytes presented signs of intense secretory activity (well-developed Golgi apparatus, abundant granular endoplasmic reticulum containing synthesized material in cisternae). Moreover, $\left[{ }^{14} \mathrm{C}\right]-$ glucosamine incorporation indicated a new synthesis either of hyaluronic acid or of proteoglycans or of both.

Analysis by autoradiography of $\left[{ }^{14} \mathrm{C}\right]$ glucosamine incorporation is now in progress. The first results show that $\left[{ }^{14} \mathrm{C}\right]$ glucosamine is incorporated in the cytoplasm of all cells and in matrix.

The evolution of the PG amount in chondrocyte aggregates and in conditioned culture medium during cultivation can be explained as follows: During the first days of culture, chondrocytes progressively aggregated and constituted cellular masses $1 \pm 2 \mathrm{~mm}$ diameter), which before Day 9 were flaky but became solid and spherical during further cultivation $(1 \mathrm{mo}$.). During the first $3 \mathrm{~d}$ of culture, chondrocytes synthesized large amounts of cartilage PG but these were released into culture medium.

Between Days 4 and 10 part of the secreted PG was integrated into an intercellular matrix. At this time, cells were close together and probably synthesized other types of molecules, such as type II collagen. This could explain why the amount of PG released into culture medium clearly decreased with time; increasing proportions of produced PG then remained inside chondrocyte aggregates. Moreover, aggregate fresh weight increased mainly during the first $6 \mathrm{~d}$ of culture.

To maintain human chondrocytes in culture with a high degree of differentiation, we consider that newly formed aggregates in culture constitute an interesting model.

\section{REFERENCES}

1. Abbot, J.; Holtzer, H. The loss of phenotypic traits by differentiated cells. III. The reversible behavior of chondrocytes in primary cultures. J. Cell. Biol. 28: 473-487; 1966.

2. Abbot, J.; Holtzer, H. The loss of phenotypic traits by differentiated cells. V. The effect of 5-bromodeoxyuridine on cloned chondrocytes. Proc. Natl. Acad. Sci. USA 59:1141-1151; 1968.

3. Adolphe, M.; Froger, B.; Ronot, X., et al. Cell multiplication and type II collagen production by rabbit articular chondrocytes cultivated in a defined medium. Exp. Cell Res. 155:527-536; 1984.

4. Archer, C. W.; Rooney, P.; Wolperts, L. Cell shape and cartilage differentiation of early chick limb bud cells in culture. Cell Differ. 11:245-251; 1982.

5. Bassleer, C.; Gysen, P.; Foidart, J. M., et al. Human chondrocytes in tridimensional culture. Morphological dif- 
ferentiation and synthesis of collagen and proteoglycans. Clin. Rheum. Drs. 3:99; 1984.

6. Benya, P. D.; Shaffer, J. D. Dedifferentiated chondrocytes reexpress the differentiated collagen phenotype when cultured in agarose gels. Cell 30:215-224; 1982.

7. Bergenholtz, A.; Lemperg, R. F. Calf articular cartilage in organ culture in a chemically defined medium. I. Autoradiographic study after [ ${ }^{35}$ S] sulfate labeling. In Vitro 11:286-290; 1975.

8. Chacko, S.; Abbott, J.; Holtzer, S., et al. The loss of phenotypic traits by differentiated cells. VI. Behavior of the progeny of a single chondrocyte. J. Exp. Med. 130:417-422; 1969.

9. Choi, Y. C.; Morris, G. M.; Lee, F. S., et al. The effect of serum on monolayer cell culture of mammalian articular chondrocytes. Connect Tiss. Res. 7:105-112; 1980.

10. Coon, H. G. Clonal stability and phenotypic expression of chick cartilage cells in vitro. Proc. Acad. Sci. USA 55:66-73; 1966.

11. Daniel, J. C.; Kosher, R. A.; Lash, J. W., et al. The synthesis of matrix components by chondrocytes in vitro in the presence of 5-bromodeoxyuridine. Cell Differ. 2:285-293; 1973.

12. Desmukh, K.; Kline, W. G. Characterization of collagen and its precursors synthesized by rabbit articular cartilage cells in various culture systems. Eur. J. Biochem. 69:117-123; 1976.

13. Foidart, J. M.; Abe, S.; Martin, G. R., et al. Antibodies to type II collagen in relapsing polychondritis. N. Engl. J. Med. 299:1203-1208; 1978.

14. Foidart, J. M.; Martin, G. R.; Abe, S., et al. Antibodies of type II collagen and circulating immune complexes in relapsing polychondritis. Collapsus Int. Centre Natl. Recherche Sci. 287:317-320; 1978.

15. Foidart, J. M.; Bere, E. W.; Yaar, M., et al. Distribution and immunoelectron microscopic localization of laminin a non collagenous basement membrane glycoprotein. Lab. Invest. 42:336-342; 1980 .

16. Foidart, J. M.; Berman, J. J.; Paglia, L., et al. Synthesis of fibronectin laminin and several collagens by a liver-derived epithelial line. Lab. Invest. 42:525-532; 1980.

17. Green, W. T., Jr.; Furgeson, R. J. Histochemical microscopic comparison of tissue produced by rabbit articular chondrocytes in vivo and in vitro. Arthritis Rheum. 18:273-280; 1975.

18. Gysen, P.; Heynen, G.; Franchimont, P. Purification de protéoglycans cartilagineux humains et aspects techniques du dosage radioimmunologique. C. R. Soc. Biol.(Paris) 174:867-877; 1980.

19. Gysen, P.; Franchimont, P. Radioimmunoassay of proteoglycans. J. Immunoassay $5: 221-243 ; 1984$.

20. Hascall, V. C.; Oegema, T. R.; Brown, M., et al. Isolation and characterization of proteoglycans from chick limb bud chondrocytes grown in vitro. J. Biol. Chem. 251:3511-3519; 1976.

21. Hascall, V. C. Interaction of cartilage proteoglycans with hyaluronic acid. J. Supramol. Struct. 7:101-120; 1977.

22. Heinegard, D. Polydispersity of cartilage proteoglycans. J. Biol. Chem. 252:1980-1989; 1977.

23. Ho, P. L.; Levitt, D.; Dorfman, A. A radioimmunostudy of the effect of bromodeoxyuridine on the synthesis of proteoglycan by differentiating limb bud cultures. Dev. Biol. 55:233-243; 1977.

24. Horwitz, A. L.; Dorfman, A. The growth of cartilage cells in soft agar and liquid suspension. J. Cell Biol. 45:342-348; 1970.

25. Katoh, Y.; Takayama, S. Isolation of highly purified chondrocytes. J. Tissue Cult. Methods 6:103-105; 1980.

26. Kuettner, K. E.; Menoli, V. A.; Pauli, B. U., et al. Synthesis of cartilage matrix by mammalian chondrocytes in vitro. II. Maintenance of collagen and proteoglycan phenotype. J. Cell Biol. 93: 751-757; 1982

27. Labarca, C.; Paigen, K. A simple rapid, and sensitive DNA assay procedure. Anal. Biochem. 102:344-352; 1980.
28. Lemperg, R. K.; Bergenholtz, A.; Smith, T. W. D. Calf articular cartilage in organ culture in a chemically defined medium. 2. Concentration of glycosaminoglycan and ${ }^{\text {ss }} \mathrm{S}$ incorporation at different oxygen tensions. In Vitro 11:291-301; 1975.

29. Levitt, D.; Dorfman, A. Control of chondrogenesis in limb bud cell cultures by bormodeoxyuridine. Proc. Natl. Acad. Sci. USA 70:2201-2205; 1973.

30. Meier, S.; Hay, E. D. Synthesis of sulfated glycosaminoglycans by embryonic corneal epithelium. Dev. Biol. 35:318-331; 1973.

31. Miller, E. J. Biochemical characteristics and biological significance of the genetically distinct collagens. Mol. Cell. Biochem. 13:165-191; 1976.

32. Nevo, Z.; Dorfman, A. Stimulation of chondromucoprotein synthesis in chondrocytes by extracellular chondromucoprotein. Proc. Natl. Acad. Sci. USA 69:2069-2072; 1972.

33. Nevo, Z.; Horwitz, A. L.; Dorfman, A. Synthesis of chondromucoprotein by chondrocytes in suspension culture. Dev. Biol. 28:219-228; 1972.

34. Norby, D. P.; Malemud, C. J.; Sokoloff, L. Differences in the collagen types synthesized by lapine articular chondrocytes in spinner and monolayer culture. Arthritis Rheum. 20:709-716; 1977.

35. Oakes, B. W.; Handley, C. J.; Lisner, F., et al. An ultrastructural and biochemical study of high density primary cultures of embryonic chick chondrocytes. J. Embryol. Exp. Morphol. 38:239-263; 1977.

36. Okayama, M.; Pacifici, M.; Holtzer, H. Differences among sulfated proteoglycans synthesized in nonchondrogenic cells, presumptive chondroblasts and chondroblasts. Proc. Natl. Acad. Sci. USA 73:3224-3228; 1976.

37. Degema, T. R., Hascall, V. C., Dziewiatkowski, D. D. Isolation and characterization or proteoglycans from the swarm rat chondrosarcoma, J. Biol. Chem. 250:6151-5159; 1975.

38. Rennard, S. I.; Berg, R.; Martin, G. R., et al. Enzyme linked immunoassay (ELISA) for connective tissue components. Anal. Biochem. 104:205-214; 1980.

39. Schwartz, E. R.; Sugumaran, G. Characteristics of human chondrocyte cultures in completely defined medium. In Vitro 18:254-260; 1982.

40. Sokoloff, L.; Malemud, C. J.; Srivastava, V. M. L., et al. In vitro culture of articular chondrocytes. Fed. Proc. 32:1499-1502; 1973.

41. Srivastava, V. M. L.; Malemud, C. J.; Sokoloff, L. Chondroid expression by lapine articular chondrocytes in spinner culture following monolayer growth. Connect. Tissue Res. 2:127-137; 1974.

42. Sternberger, L. A.; Hardy, P. A.; Cuculis, J. J., et al. The unlabelled antibody enzyme method of immunohistochemistry and properties of soluble antigen-antibody complex and its use in identification of spirochetes. J. Histochem. Cytochem. 18:315-333; 1970.

43. Toole, B. P.; Jackson, G.; Gross, J. Hyaluronate in morphogenesis inhibition of chondrogenesis in vitro. Proc. Natl. Acad. Sci. USA 69:1384-1386; 1972.

44. Trelstad, R. L. Le collagène. La Recherche 12:312-321; 1981.

45. Vertel, B. M.; Dorfman, A. An immunohistochemical study of extracellular matrix formation during chondrogenesis. Dev. Biol. 62:1-12; 1978.

46. Vertel, B. M.; Dorfman, A. Simultaneous localization of type II collagen and core protein of chondroitin sulfate proteoglycan in individual chondrocytes. Proc. Natl. Acad. Sci. USA $76: 1260-1264 ; 1979$

47. Von Der Mark, K.; Gauss, V.; Von Der Mark, H., et al. Relationship between cell shape and type of collagen aynthesized as chondrocytes lose their cartilage phenotype in culture. Nature 267:531-532; 1977. 